\title{
A novel real-time polymerase chain reaction-based method for the detection and quantification of lactose-fermenting Enterobacteriaceae in the dairy and other food industries
}

\author{
M. C. Martín, ${ }^{1}$ N. Martínez, ${ }^{1}$ B. del Rio, V. Ladero, M. Fernández, and M. A. Alvarez ${ }^{2}$ \\ Instituto de Productos Lácteos de Asturias, CSIC, 33300 Villaviciosa, Asturias, Spain
}

\begin{abstract}
The presence of lactose-fermenting Enterobacteriaceae and coliforms is routinely assessed to determine the hygienic quality of water and foods, particularly dairy products. This paper reports the use of lac $Z$-specific primers in an SYBR green I-based real-time PCR method for the easy and rapid detection of coliforms in dairy products. A large number of bacterial species were assayed to establish the specificity of the method. The sensitivity of the method was assessed using artificially contaminated cheeses. The limit of detection was 1 coliform cell in cheese samples enriched for $8 \mathrm{~h}$ in a culture medium. The entire procedure, including sample processing, enrichment, DNA extraction, and real-time PCR amplification, can be completed within 10 to $12 \mathrm{~h}$, making it a single-day assay.
\end{abstract}

Key words: Enterobacteriaceae, coliform, real-time polymerase chain reaction detection, cheese

\section{INTRODUCTION}

Coliforms are a broad class of bacteria defined as rod-shaped, gram-negative, non-spore-forming microorganisms that ferment lactose with the production of acid and gas when incubated at 35 to $37^{\circ} \mathrm{C}$. The presence of coliforms can be used to assess the hygienic quality of foods and water (Feng and Hartman, 1982; Bredie and de Boer, 1992). These microorganisms are abundant in the feces of warm-blooded animals, but are also found in aquatic environments, in soil, and on vegetation (Winfield and Groisman, 2003). Although coliforms do not usually cause sickness, their presence in food and the ease with which they can be cultured make them useful indicators of the possible presence of other, more pathogenic organisms of fecal origin (Leclerc et al., 2001).

Received June 12, 2009.

Accepted November 25, 2009.

${ }^{1}$ These authors contributed equally to this work.

${ }^{2}$ Corresponding author: maag@ipla.csic.es
Microbiologically, cheeses are considered to be among the safest of foods. Like other milk products, however, they can transmit pathogenic bacteria. The organisms responsible for infections associated with cheese consumption include Salmonella, Listeria monocytogenes, and verocytotoxin-producing Escherichia coli (Zottola and Smith, 1991; De Buyser et al., 2001). Careful investigations have shown the sources of contamination to be raw milk, inadequately pasteurized milk, or postpasteurization contamination with organisms originally derived from raw milk or the manufacturing environment (Murphy and Boor, 2000).

Coliform bacteria are an important indicator of the hygienic standards maintained in dairy product manufacture, processing, and storage (including the storage of the milk used in their production; APHA, 2004). In the dairy farm setting, coliform counts provide a useful indicator of the extent of fecal contamination of milk, a recognized index of the hygienic standards maintained. Because milk pasteurization easily kills coliform bacteria, their detection in pasteurized products indicates inadequate practices during manufacture or packaging. Although the presence of these organisms certainly constitutes a food safety problem, they can also produce off flavors and reduce the shelf life of dairy products.

The traditional methods for detecting coliforms rely upon culturing in a medium that selectively permits the growth of gram-negative bacteria and differentially detects lactose-utilizing organisms (APHA, 2005). However, this is laborious, expensive, and time consuming (Bredie and de Boer, 1992); a more practical, rapid method is therefore needed. In recent years, methods based on PCR have been successfully used (Bej et al., 1990, 1991; Tantawiwat et al., 2005), and real-time quantitative PCR (RT-qPCR), which offers the advantages of speed and sensitivity, is now routinely used to detect pathogen bacteria in different food matrices, including pathogen coliform strains (Holicka et al., 2006; Bohaychuk et al., 2007; Elizaquível and Aznar, 2008; Cheng et al., 2009; Omiccioli et al., 2009). However, to our knowledge, the present study reports the first RT-qPCR method for the simultaneous detection of all coliform species in a single assay, which is based 
Table 1. Strains used in this work

\begin{tabular}{|c|c|}
\hline Strain $^{1}$ & $\mathrm{RT}-\mathrm{qPCR}{ }^{2}$ \\
\hline Klebsiella pneumoniae ssp. rhinoscleromatis CECT 852 & + \\
\hline Klebsiella pneumoniae ssp. pneumoniae CECT 143 & + \\
\hline Klebsiella pneumoniae ssp. ozaenae CECT 851 & + \\
\hline Klebsiella oxytoca CECT 860 & + \\
\hline Enterobacter cloacae CECT 194 & + \\
\hline Enterobacter aerogenes CECT 684 & + \\
\hline Enterobacter gergoviae CECT 857 & + \\
\hline Enterobacter sakazakii CECT 858 & + \\
\hline Citrobacter freundii CECT 401 & + \\
\hline Citrobacter amalonaticus CECT 863 & + \\
\hline Citrobacter koseri CECT 856 & + \\
\hline Escherichia coli CECT 423 & + \\
\hline Escherichia coli CECT 428 & + \\
\hline Escherichia coli CECT 515 & + \\
\hline Escherichia coli CECT 434 & + \\
\hline Escherichia coli CECT 4201 & + \\
\hline Escherichia coli CECT 470 & + \\
\hline Escherichia coli CECT 405 & + \\
\hline Salmonella typhimurium CECT 4594 & - \\
\hline Salmonella virchow CECT 4154 & - \\
\hline Salmonella virchow LSP $16 / 94$ & + \\
\hline Streptococcus thermophilus CNRZ 1066 & - \\
\hline Streptococcus thermophilus LMD9 & - \\
\hline Lactobacillus casei ATCC 393 & - \\
\hline Lactobacillus paracasei CECT 4175 & - \\
\hline Lactobacillus fermentum CECT 4007 & - \\
\hline Lactobacillus reuteri CECT 925 & - \\
\hline Lactobacillus plantarum CECT 3801 & - \\
\hline Lactobacillus delbrueckii ssp. bulgaricus CECT 4005 & - \\
\hline Lactobacillus buchnerii CECT 4683 & - \\
\hline Lactobacillus curvatus CECT 904 & - \\
\hline Lactobacillus brevis CECT 4121 & - \\
\hline Lactococcus lactis IL1403 (Chopin et al., 1984) & - \\
\hline Lactococcus lactis CECT 697 & - \\
\hline Lactococcus lactis CECT 539 & - \\
\hline Raoultella planticola CECT 843 & + \\
\hline Raoultella terrígena CECT 4519 & + \\
\hline Bacillus cereus CECT 131 & - \\
\hline Bacillus subtilis CECT 356 & - \\
\hline Bacillus coagulans & - \\
\hline Clostridium argentinense CECT 4615 & - \\
\hline Clostridium sporogenes CECT 892 & - \\
\hline Clostridium perfringens CECT 376 & - \\
\hline Clostridium acetobutylicum CECT 508 & - \\
\hline Clostridium difficile CECT 531 & - \\
\hline Clostridium tyrobutyricum CECT 4011 & - \\
\hline Enterococcus casseliflavus CECT 969 & - \\
\hline Enterococcus faecalis CECT 795 & - \\
\hline Enterococcus faecalis CECT 4176 & - \\
\hline Enterococcus mundtii CECT 972 & - \\
\hline Enterococcus faecium CECT 410 & - \\
\hline Enterococcus durans CECT 411 & - \\
\hline Enterococcus hirae CECT 279 & - \\
\hline Listeria monocytogenes CECT 940 & - \\
\hline Listeria ivanovii CECT 913 & - \\
\hline Listeria innocua CECT 910 & - \\
\hline Micrococcus luteus CECT 245 & - \\
\hline Staphylococcus aureus CECT 435 & - \\
\hline Shigella flexneri CECT 585 & - \\
\hline Shigella sonnei CECT 413 & + \\
\hline Pseudomonas putida CECT 324 & - \\
\hline Pseudomonas fluorescens CECT 378 & - \\
\hline Serratia marcescens CECT 846 & - \\
\hline Yersinia enterocolitica CECT 4315 & - \\
\hline Hafnia alvei CECT 158 & - \\
\hline Edwardsiella ictaluri CECT 885 & - \\
\hline
\end{tabular}

Table 1 (Continued). Strains used in this work

\begin{tabular}{lc}
\hline Strain $^{1}$ & RT-qPCR $^{2}$ \\
\hline Providencia stuartii CECT 866 & - \\
Erwinia carotovora CECT 314 & - \\
Rhodococcus equi CECT 555 & - \\
Moraxella catarrhalis ATCC 25238 & - \\
\hline
\end{tabular}

${ }^{1} \mathrm{CECT}=$ Colección Española de Cultivos Tipo, Burjasot, Valencia, Spain; LSP = Laboratorio de Salud Pública, Principado de Asturias, Spain; CNRZ = Centre National de Recherché Zootechniques, Jouyen-Josas, France; LMD = Laboratory of Microbiology, Technical University, Delft, the Netherlands; ATCC = American Type Culture Collection, Rockville, Maryland.

${ }^{2} \mathrm{RT}-\mathrm{qPCR}=$ real-time quantitative PCR; + indicates a positive RT$\mathrm{PCR}$ result, - indicates a negative result.

on oligonucleotide primers targeting a segment of the $\beta$-galactosidase gene (lacZ) and the use of SYBR green I as a fluorescent dye.

\section{MATERIALS AND METHODS}

\section{Bacterial Strains}

A total of 70 strains, including positive and negative controls, were used in this work (Table 1). All Enterobacteriaceae strains were grown at $37^{\circ} \mathrm{C}$ in brain heart infusion (BHI; Oxoid, Basingstoke, UK) with aeration. Viable numbers were determined on $2 \%$ violet red bile agar (with 4-methyl-umbelliferyl $\beta$-D-glucuronide; Oxoid) and brilliant green lactose bile (APHA, 2005). Streptococcus thermophilus was grown at $42^{\circ} \mathrm{C}$ in M17 broth (Oxoid) supplemented with $0.5 \%$ glucose and $0.5 \%$ lactose (GLM17) or 2\% M17 agar. Lactobacillus casei was grown at $37^{\circ} \mathrm{C}$ in de Man, Rogosa, Sharpe (MRS) broth (Oxoid) or on 2\% MRS agar. Lactococcus lactis was grown at $30^{\circ} \mathrm{C}$ in GLM17 broth or on $2 \%$ GLM17 agar.

\section{Extraction of DNA for the RT-qPCR Assay}

Two methods were used to extract DNA from bacterial cells: lysis by boiling, or the use of the Genelute Bacterial Genomic DNA kit (Sigma, St. Louis, MO). Culture samples of $1 \mathrm{~mL}$ were used in both methods. In the first method, the bacterial suspension was centrifuged at 10,000 $\times g$ for $5 \mathrm{~min}$ and the sediment was resuspended in $0.85 \% \mathrm{NaCl}$ before being centrifuged again at $10,000 \times g$ for $5 \mathrm{~min}$. The washed sediment was resuspended in $100 \mu \mathrm{L}$ of PCR buffer $(10 \mathrm{~m} M$ Tris $\left.\mathrm{HCl}, 25 \mathrm{~m} M \mathrm{KCl}, 5 \mathrm{~m} M\left(\mathrm{NH}_{4}\right)_{2} \mathrm{SO}_{4}, 2 \mathrm{~m} M \mathrm{MgCl}_{2}\right)$ and incubated at $95^{\circ} \mathrm{C}$ for 30 min (Oravcová et al., 2007). In the second method, the manufacturer's instructions were followed. The DNA was eluted in $100 \mu \mathrm{L}$ of molecular biology grade water (Sigma). 


\section{lacZ Sequencing and Nucleotide Sequence Analysis}

An internal fragment of the lacZ gene from different coliform species was amplified with the lacZ-1 (5'-ATGAAGCAGAACAACTTCAACGCCGT-3') and lacZ-4R (5'-CGCCGATGTCGTTGTCCAGCGG-3') oligonucleotides (Sigma Genosys, Haverhill, UK). For this, a loopful of bacteria from an agar culture was resuspended in a PCR mixture consisting of $1 \times \mathrm{PCR}$ buffer, $0.2 \mathrm{~m} M$ deoxynucleoside triphosphates, $0.2 \mathrm{mM}$ of each oligonucleotide primer, $2 \mathrm{U}$ of DyNAzyme II DNA polymerase (Finnzymes Oy, Espoo, Finland), and nanopure water in a final volume of $50 \mu \mathrm{L}$. The PCR amplification was performed using a DNA thermocycler (iCycler, Bio-Rad, Hercules, CA). Denaturing was performed at $95^{\circ} \mathrm{C}$ for $5 \mathrm{~min}$. This was followed by 30 cycles at $95^{\circ} \mathrm{C}$ for $60 \mathrm{~s}, 60^{\circ} \mathrm{C}$ for $60 \mathrm{~s}$, and $72^{\circ} \mathrm{C}$ for $90 \mathrm{~s}$, and a final incubation at $72^{\circ} \mathrm{C}$ for $10 \mathrm{~min}$. The PCR products were purified using the GFX PCR DNA and Gel Band Purification kit (Amersham Biosciences, Buckinghamshire, UK). Nucleotide sequences were determined using an ABI Prism 373 Stretch automated sequencer (Secugen S.L., Madrid, Spain). Sequence data were assembled and analyzed using a sequence analysis software package available from the EMBL Spanish node (CNB, CSIC, Madrid, Spain). Alignment was performed using the CLUSTAL W algorithm (Thompson et al., 1994).

\section{RT-qPCR Conditions}

Real-time qPCR amplification of small regions of the lac $Z$ genes was performed in a total volume of $20 \mu \mathrm{L}$ containing $1 \mu \mathrm{L}$ of template, $10 \mu \mathrm{L}$ of Power SYBR Green PCR Master Mix (Applied Biosystems, Warrington, UK), and $900 \mathrm{n} M$ of each primer. The 7500 Fast Real-Time PCR System (Applied Biosystem) was used for thermocycling and to record changes in fluorescence. The PCR reaction was initiated with preincubation at $50^{\circ} \mathrm{C}$ for 2 min followed by denaturation at $95^{\circ} \mathrm{C}$ for $10 \mathrm{~min}$, and then 40 cycles of denaturation at $95^{\circ} \mathrm{C}$ for $15 \mathrm{~s}$ plus annealing at $55^{\circ} \mathrm{C}$ for $60 \mathrm{~s}$. Melting curve analysis was performed immediately after the final PCR cycle to determine the specificity of the reaction. The reactants were incubated at $95^{\circ} \mathrm{C}$ for $15 \mathrm{~s}$, annealing at $55^{\circ} \mathrm{C}$ for $1 \mathrm{~min}$ and then slowly increasing the temperature to $95^{\circ} \mathrm{C}$. Fluorescence was monitored continuously. Negative controls were included, containing all the elements of the reaction mixture except the template. All samples were processed in duplicate.

\section{Data Analysis}

Data analyses were performed using Applied Biosystems 7500 Fast Real-Time PCR System software
(Sequence Detection System v. 1.3). In the 7500 Fast Real-Time PCR System, the fluorescence of SYBR green is calibrated dynamically against the fluorescence of Rox, a passive internal reference dye. The cycle threshold $\left(\mathbf{C}_{t}\right)$ is defined as the PCR cycle during which the increase in the SYBR green fluorescence crosses the chosen threshold (in this case, the default set by the manufacturer). The $\mathrm{C}_{t}$ value is inversely related to the copy number of the target gene. A sample was considered positive for the presence of coliforms if the $\mathrm{C}_{\mathrm{t}}$ value was at least $2 \mathrm{U}$ below that recorded for the negative control.

\section{Artificial Contamination and Enrichment of Cheese}

Cheeses were artificially contaminated based on a procedure previously described (Hein et al., 2001). Escherichia coli CECT 515, Enterobacter cloacae CECT 194, Citrobacter freundii CECT 401, or Klebsiella pneumoniae ssp. pneumoniae CECT 143 were cultured in $\mathrm{BHI}$ broth overnight at $37^{\circ} \mathrm{C}$ and 10 -fold serially diluted in BHI. The number of bacteria per milliliter was determined by the viable count on $2 \%$ violet red bile agar (with 4-methyl-umbelliferyl $\beta$-D-glucuronide). For the enrichment step, $25 \mathrm{~g}$ of Emmental cheese samples were homogenized in $225 \mathrm{~mL}$ of BHI (Oxoid) using a LabBlender 400 Stomacher (Seward Ltd., London, UK). Equal numbers of the 4 bacterial species were added to the stomacher bags to final concentrations of 1,10 , and $100 \mathrm{cfu} / \mathrm{mL}$. These samples were enriched at $37^{\circ} \mathrm{C}$ for 0 , $2,3,4,5,6,7,8$, or $24 \mathrm{~h}$. All cheese samples used were previously confirmed to be negative for coliforms.

\section{Nucleotide Sequence Accession Numbers}

The nucleotide sequences of the $l a c Z$ genes were deposited in the European Molecular Biology Laboratory database (http://www.ebi.ac.uk/Clustal W/) under accession numbers FN297863 (E. coli CECT 515), FN297864 (E. coli CECT 428), FN297865 (E. coli CECT 423), FN297866 (Enterobacter sakazakii CECT 858), FN297867 (K. pneumoniae ssp. rhinoscleromatis CECT 852), FN297868 (K. pneumoniae ssp. ozaenae CECT 851), FN297869 (K. pneumoniae ssp. pneumoniae CECT 143), FN297870 (C. freundii CECT 401), FN297871 (Citrobacter koseri CECT 856), FN297872 (Citrobacter amalonaticus CECT 863), and FN297873 (Raoultella planticola CECT 853).

The accession numbers of the sequences obtained from databases are C. freundii MF466 (AY746954), C. freundii OS60 (AY746953), E. coli K12 W3110 (AC_000091), E. coli K12 MG1655 (U00096), E. coli O157:H7 EDL933 (NC_002655), E. coli O157:H7 Sakai (NC_002695), Ent. cloacae B5 (DQ266449), Ent. cloacae (D42077), 
C. freundii MF466

C. freundii os60

E. coli K12 W3110

E. coli K12 MG1655

E. Coli 0157:H7 EDL933

E. Coli 0157:H7 Sakai

Ent. cloacae B5

Ent. cloacae

Ent. cloacae 10.2-45

Ent. cloacae E482

K. pneumoniae

E.coli CECT515

E. COli CECT 428

E. COli CECT 423

Ent.sakazakii CECT858

K.pneumoniae CECT852

K.pneumoniae CECT851

$K$.pneumoniae CECT143

C. freundii CЕСT 401

C.koseri СЕСТ856

C.amalonaticus CECT 863

R.planticola CECT 843
TCGCTACGGCCTGTATGTGGTCGACGAAGCCAACATTGAAACCCACGGCATGGTGCCGATGAA TCGTTACGGCCTGTATGTCGTCGACGAAGCCAATATTGAAACCCACGGCATGGTGCCGATGAA CCGCTACGGCCTGTATGTGGTGGATGAAGCCAATATTGAAACCCACGGCATGGTGCCAATGAA CCGCTACGGCCTGTATGTGGTGGATGAAGCCAATATTGAAACCCACGGCATGGTGCCAATGAA CCGCTACGGCCTGTATGTGGTGGATGAAGCCAATATTGAAACCCACGGCATGGTGCCAATGAA CCGCTACGGCCTGTATGTGGTGGATGAAGCCAATATTGAAACCCACGGCATGGTGCCAATGAA TCGCTACGGGCTGTACGTCGTTGACGAAGCCAATATTGAAACCCACGGCATGGTGCCGATGAG TCGCTACGGGCTGTACGTCGTTGACGAAGCCAATATCGAAACGCACGGCATGGTGCCGATGAG CCGCTACGGGCTGTACGTCGTTGACGAAGCCAATATCGAAACGCACGGCATGGTGCCGATGAG TCGCTACGGCCTGTACGTGGTCGATGAGGCGAATATTGAAACCCACGGCATGGTGCCGATGAG CCGCTACGGTCTGTACGTGGTCGATGAAGCCAATATTGAAACCCACGGGATGGTGCCGATGAA CCGCTACGGCCTGTATGTGGTGGATGAAGCCAATATTGAAACCCACGGCATGGTGCCAATGAA CCGCTACGGCCTGTATGTGGTGGATGAAGCCAATATTGAAACCCACGGCATGGTGCCAATGAA CCGCTACGGCCTGTATGTGGTGGATGAAGCCAATATTGAAACCCACGGCATGGTGCCAATGAA CCACTACGGCCTGTATGTGGTGGATGAAGCCAACATTGAAACCCACGGCATGGTGCCAATGAA CCGCTACGGTCTGTACGTGGTCGATGAAGCCAATATTGAAACCCACGGGATGGTGCCGATGAA CCGCTACGGTCTGTACGTGGTCGATGAAGCCAATATTGAAACCCACGGGATGGTGCCGATGAA CCGCTACGGTCTGTACGTGGTCGATGAAGCCAATATTGAAACCCACGGGATGGTGCCGATGAA TCGCTACGGCTTGTATGTCGTCGACGAAGCCAACATTGAAACCCACGGCATGGTGCCGATGAA TCGCTACGGCCTGTACGTGGTGGATGAGGCCAATATCGAAACCCACGGCATGGTGCCGATGAA TCGCTATGGTCTGTATGTGGTGGATGAGGCCAACATCGAAACCCACGGCATGGTGCCGATGAA CCGCTACGGCCTGTACGTGGTCGATGAGGCGAACATCGAAACCCATGGCATGGTGCCAATGAA

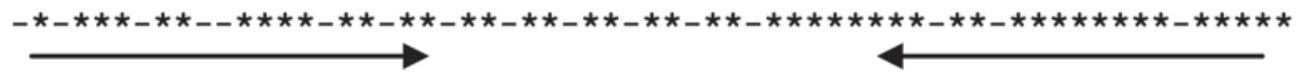

LacZ-7
LacZ-6R

Figure 1. Alignment of a 63-bp region of the $\beta$-galactosidase (lacZ) gene from 22 representative coliform strains (Citrobacter freundii, Escherichia coli, Enterobacter cloacae, Klebsiella pneumoniae, Enterobacter sakazakii, Citrobacter koseri, Citrobacter amalonaticus, and Raoultella planticola) using Clustal W software (Altschul et al., 1997). The locations of the primers are shown by arrows, an asterisk denotes identical sequences, and a dash indicates a mismatch with the consensus sequence.

Ent. cloacae 10.2-45 (AY746948), Ent. cloacae E482 (AY746947), and K. pneumonia (M11441).

\section{RESULTS}

\section{Sequencing of the lacZ Genes and Primer Design}

Near-complete DNA sequences of the lac $Z$ gene were obtained by sequencing a 1.2 -kb internal fragment obtained by PCR amplification (primers lacZ-1 and lacZ-4R) from 11 different coliforms strains. The obtained sequences, together with 11 sequences from databases, were compared and aligned using BLAST (Altschul et al., 1997) and Clustal W software (Chenna et al., 2003). The alignment of the 22 lac $Z$ nucleotide sequences allowed the design of a degenerate oligonucleotide primer pair for RT-qPCR: forward primer lacZ-7 5'-CGCTACGGYCTGTAYGTSGT-3' and reverse primer lacZ-6R 5'-TCATCGGCACCATSCCGTG-3' (Figure 1).

\section{Optimization of RT-qPCR}

Real-time qPCR reaction mixes were produced to provide at least 3 replicates of each of the following forward:reverse primer concentration (n $M$ ) combinations: 100:100, 100:300, 100:600, 100:900, 300:100, 300:300, 300:600, 300:900, 600:100, 600:300, 600:600, 600:900, 900:100, 900:300, 900:600, and 900:900. The lowest and highest $C_{t}$ values were obtained with the 900:900 and 100:100 combinations, respectively (data not shown). The 900:900 combination was chosen as the optimal combination for use in subsequent experiments. Thermocycling was optimized in terms of annealing temperature (tests were performed between 50 and $60^{\circ} \mathrm{C}$ with a $60 \mathrm{~s}$ elongation step; a temperature of $55^{\circ} \mathrm{C}$ produced the earliest $\mathrm{C}_{\mathrm{t}}$ responses) and extension step time.

\section{Specificity and Sensitivity}

The specificity of the assay was tested using a panel of different bacterial strains from culture collections (Table 1). The specificity of the method was assessed by comparing the amplification products and melting curves. Only lacZ-positive Enterobacteriaceae were detected. As expected, Shigella flexneri and Salmonella virchow CECT 4154, which are lactosenegative Enterobacteriaceae, were undetected. However, it is important to note that Shigella sonnei and 

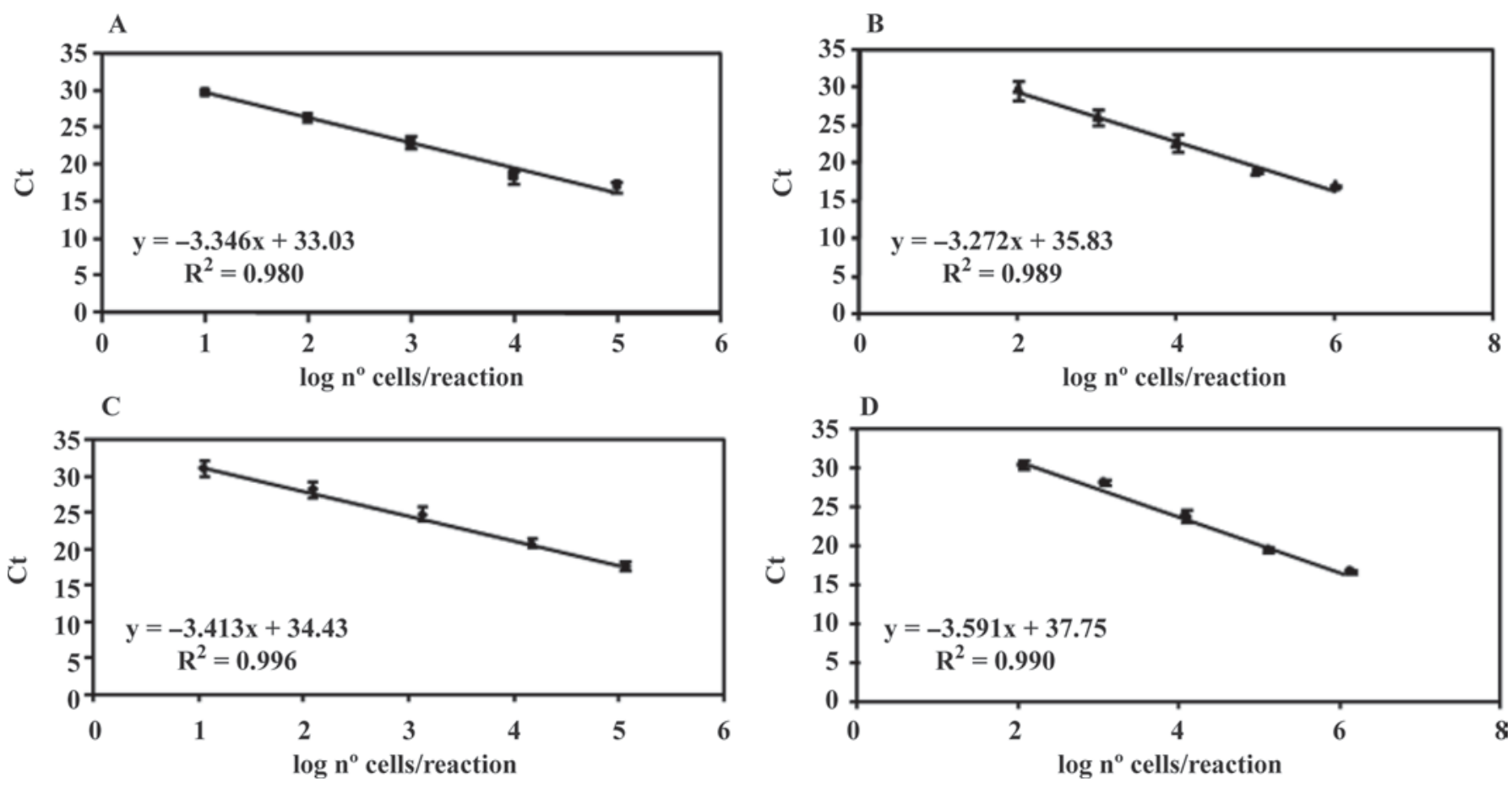

Figure 2. Standard curves for the log number of coliform cells per reaction versus the cycle threshold $\left(\mathrm{C}_{t}\right)$ value for the fluorescent signal for A) Escherichia coli CECT 515, B) Enterobacter cloacae CECT 194, C) Citrobacter freundii CECT 401, and D) Klebsiella pneumoniae ssp. pneumoniae CECT 143. The error bars indicate standard deviations for 3 independent experiments. CECT = Colección Española de Cultivos Tipo, Burjasot, Valencia, Spain.

Salmonella virchow LSP 16/94, both of which are lactose-positive strains (Martín et al., 2001), were detected.

In the first step of the validation procedure, the dynamic range of quantification and the sensitivity of the assay were investigated. For this purpose, a 10-fold dilution series of E. coli CECT 515 was used (Figure $2 \mathrm{a})$. The limit of detection was 10 cells per reaction, when 2 out of 3 measurements were positive. The linear range of quantification was 5 logarithmic decades, with a correlation coefficient of 0.9802 for triplicate measurements. The slope of the curve for lac $Z$ gene was -3.463 . Another important variable, the PCR reaction efficiency $\left(\mathrm{E}=10^{1 /-\mathrm{S}}-1\right.$, where $\mathrm{S}=$ slope $)$, can be obtained from the standard curve if the correlation coefficient is high (Klein et al., 1999); in this case the calculated efficiency was 0.9443 .

The limit of detection for $C$. freundii CECT 401, Ent. cloacae CECT 194, and K. pneumoniae ssp. pneumoniae CECT 143 were 10, 100, and 100 cells per reaction, respectively (Figure 2b, 2c, and 2d). The linear range of quantification was 5 logarithmic decades: the $\mathrm{r}^{2}$ values were $0.9968,0.9897$, and 0.9906 , respectively. The slopes of the curves were $-3.4138,-3.2729$, and -3.5912 , respectively; the efficiency of the reaction was $0.9630,1.02$, and 0.8987 , respectively.

\section{Melting Curve Analysis of the Amplified DNA}

Real-time qPCR data were further analyzed by determining the melting temperature of each amplification product. Melting temperature is dependent upon the length of the amplified DNA and the G/C content of the sequence. The values obtained were $76.3^{\circ} \mathrm{C}$ for $E$. coli $\mathrm{CECT} 515,78^{\circ} \mathrm{C}$ for $C$. freundii $\mathrm{CECT} 401,77.2^{\circ} \mathrm{C}$ for Ent. cloacae CECT 194, and $76.4^{\circ} \mathrm{C}$ for K. pneumoniae ssp. pneumoniae CECT 143.

\section{RT-qPCR Detection Limits}

To develop a universal protocol for food monitoring, $25 \mathrm{~g}$ of cheese was artificially contaminated in 2 independent experiments with decreasing amounts of an overnight culture of E. coli CECT 515, C. freundii CECT 401, Ent. cloacae CECT 194, or K. pneumoniae ssp. pneumoniae CECT $143(100 \mu \mathrm{L}$ of 10 -fold dilutions in BHI to provide $10^{6}$ down to $10 \mathrm{cfu} / \mathrm{g}$ ). The contaminated cheeses were subjected to enrichment in BHI for $2,3,4,5,6,7,8$, or $24 \mathrm{~h}$. The DNA extraction was then performed; this was best done using the Genelute Bacterial Genomic DNA kit (Sigma). Real-time qPCR amplification was performed as described in Materials and Methods. The results are shown in Table 2. 
Table 2. Detection of coliforms in cheese by culture enrichment and real-time quantitative $\mathrm{PCR}^{1}$

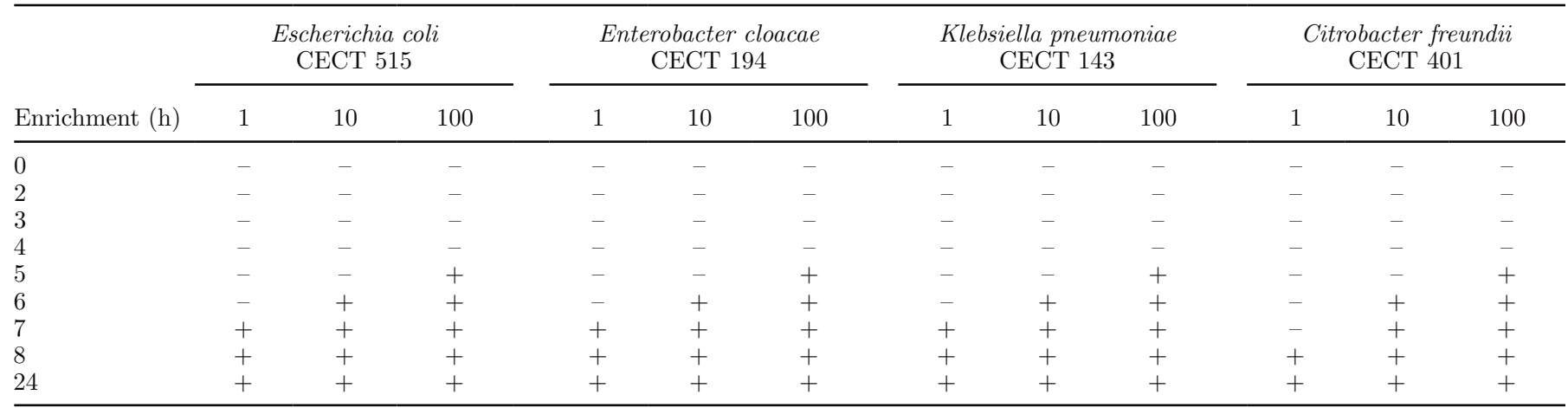

${ }^{1} \mathrm{CECT}=$ Colección Española de Cultivos Tipo, Burjasot, Valencia, Spain; 1, 10, and 100 indicate the contamination level of coliforms (cfu/mL) before enrichment; + indicates a positive RT-PCR result, - indicates a negative result.

When cheeses were contaminated with $1 \mathrm{cfu} / \mathrm{mL}, E$. coli, Ent. cloacae, and K. pneumoniae were detectable after $7 \mathrm{~h}$ of enrichment (Table 2). At this time, the average number of $\mathrm{cfu} / \mathrm{mL}$ reached $1 \times 10^{5}$ for $E$. coli and Ent. cloacae and $2 \times 10^{5}$ for K. pneumoniae. Eight hours of enrichment were necessary for the detection of C. freundii, at which time the culture contained a mean $1 \times 10^{5} \mathrm{cfu} / \mathrm{mL}$. When the initial contamination was 10 $\mathrm{cfu} / \mathrm{mL}$ and $100 \mathrm{cfu} / \mathrm{mL}$, detection was possible after 6 and $5 \mathrm{~h}$ of enrichment, respectively.

\section{DISCUSSION}

The enumeration of coliforms, and more specifically of $E$. coli, in food and water is of major importance because it provides a means of assessing the hygienic quality of the latter (Feng and Hartman, 1982; Bredie and de Boer, 1992). The traditional methods for detecting bacteria in food are labor intensive and time consuming; the past $10 \mathrm{yr}$ has therefore seen the development of several faster and less tedious procedures. Those based on RT-qPCR have demonstrated great potential, not only because of the ability to quantify the target but also because of their specificity, sensitivity, and rapidity. Primers directed toward the E. coli enterotoxin gene, used as part of a suite of real-time SYBR green assays for the detection of food- and waterborne pathogenic strains in feces (Fukushima et al., 2003), and RT-qPCR methods that use fluorescent probes for monitoring microbial levels in water and different foods (Foulds et al., 2002; Cheng et al., 2009; Omiccioli et al., 2009), have been developed. To our knowledge, however, a single RT-qPCR assay for the detection of all coliform species has not been previously proposed. In the present study, a set of lacZ-targeted, species- and group-specific primer pairs was designed and optimized for the accurate detection of coliforms in cheese samples. These were analyzed by RT-qPCR involving SYBR green I, a nonspecific, double-stranded, DNA-binding dye that does not require the design of specific probes and the binding of which is not affected by potential mutations of the target gene. The method is reliable and sensitive with a wide dynamic detection range (at least 5 orders of magnitude), shows good linearity $\left(\mathrm{r}^{2}\right.$ between 0.9802 and 0.9968 ) and PCR efficiency (E between 0.8987 and 1.02 ), and has a very low detection limit (as few as 10 coliforms per reaction). The ranges in these values could be caused by mismatches between the oligonucleotide primers and the target sequences of the different strains, which would affect the annealing temperature.

Because the method is based on the detection of lacZ, it is able to detect coliform bacteria, including members of the genera Escherichia, Klebsiella, Citrobacter, and Enterobacter, but also lactose-positive Shigella and Salmonella strains. Lactose fermentation is a biochemical property used to distinguish Shigella ssp. from E. coli. However, there are some Shigella strains that can ferment lactose (although relatively slowly); after cultivation for $2 \mathrm{~d}$ or more, their colonies show a lactosefermenting phenotype (Powe and Gross, 1984). Southern hybridization analysis has revealed that a region homologous to E. coli lac $Z$ is present in lactose-positive Shigella strains Shigella dysenteriae serovar 1 and Shigella sonnei (Ito et al., 1991). Indeed, the analysis of the complete genome sequences of Sh. dysenteriae and Sh. sonnei has revealed the presence of the lac $Z$ gene (Yang et al., 2005). It has not been found, however, in Shigella flexneri (Wei et al., 2003).

A substantial number of genes can be inserted into, deleted from, or rearranged within genomes during evolution. The idea that the lac operon could be acquired via horizontal transfer, allowing it to invade a new niche and form new species, has become a paradigmatic example of bacterial adaptation and specialization (Ochman et al., 2000).

Traditionally, Salmonella are considered non-lactosefermenting bacteria. However, a small but important number of strains in this highly diverse group are able 
to ferment this sugar. Lactose-positive Salmonella ssp. strains have been detected sporadically in the past (Usera et al., 1998; Martín et al., 2001). The RT-qPCR method proposed in this work was able to detect an atypical lactose-fermenting Salmonella virchow isolated during an outbreak of food poisoning associated with the consumption of infant formula.

The genus Klebsiella is a heterogeneous group that has been divided into 3 clusters (Drancourt et al., 2001). Cluster I includes K. pneumoniae ssp. pneumoniae, K. pneumoniae ssp. rhinoscleromatis, and $K$. pneumoniae ssp. ozaenae; cluster II comprises Klebsiella ornithinolytica, Klebsiella planticola, Klebsiella trevisanii, and Klebsiella terrigena; and cluster III includes Klebsiella oxytoca. Recently, the analysis of $16 \mathrm{~S}$ ribosomal DNA and $r p o B$ sequences led to the subdivision of the genus Klebsiella into 2 genera-Klebsiella and Raoultellathe latter of the 2 containing the species of cluster II (Drancourt et al., 2001). As expected, the method proposed in this work detected species of the 3 clusters, including those from the new genus Raoultella. Current molecular microbiology methods allow a more precise identification of bacteria and highlight the imprecision of certain traditional methods. Nowadays it would seem more appropriate to speak of lactose-fermenting Enterobacteriaceae than coliforms.

In comparison with previous RT-qPCR assays, which are focused on the detection of pathogen species such as Salmonella ssp. (Omiccioli et al., 2009) or even just pathogen strains of $E$. coli O157, the proposed method allowed the detection of all the lactose-fermenting Enterobacteriaceae species, including those belonging to Klebsiella, Citrobacter, and Enterobacter genera. Although most of the coliform strains are not pathogens, their quantification allows an investigator to determine the hygienic quality of foods and indicates the possible presence of pathogen organisms of fecal origin. In this regard, it is noteworthy that this method was faster (detection in less than $12 \mathrm{~h}$ ) and more sensitive (1 cfu/ $\mathrm{mL}$ ) than previous methods, including culture and PCR methods.

The reliability of PCR detection methods depends, in part, on the presence of a sufficient number of target cells (Feng, 1997). Because foods comprise complex matrices, most commercially available detection systems require selective enrichment steps to overcome problems of low pathogen numbers (Hill, 1996). A major challenge in developing a rapid RT-qPCR-based method for the detection of pathogenic bacteria in food is the optimization of the enrichment procedure to make it as short as possible, but providing sufficient target cells for downstream analysis. In the most difficult case met in the present work in this respect- that of $C$. freundii
CECT 401-a minimum $8 \mathrm{~h}$ of enrichment culture was required for detection to be possible. Therefore, the recommended time of enrichment to ensure the hygienic quality of the cheeses would be at least $8 \mathrm{~h}$. The processing of the samples, the extraction of bacterial DNA, and RT-qPCR amplification takes between 2 and $4 \mathrm{~h}$.

In conclusion, the proposed RT-qPCR was shown to be an effective, sensitive, and rapid single-day method for the detection of lactose-fermenting Enterobacteriaceae in cheese. It is important to note that small modifications to the procedure should allow the detection of these bacteria in drinking water (which should be easier because of the more favorable characteristics of the matrix) and in other types of food, including other dairy products.

\section{ACKNOWLEDGMENTS}

We are grateful to Corporación Alimantaria Peñasanta S.A. (CAPSA, Granda, Asturias, Spain) for its support of this work. N. Martínez, B. del Río, and V. Ladero were beneficiaries of I3P CSIC contracts financed by the European Social Fund (Brussels, Belgium). This research was also supported by project IE05-125 from the Fundación para el Fomento en Asturias de la Investigación Científica Aplicada y la Tecnología (FICYT; Asturias, Spain).

\section{REFERENCES}

Altschul, S. F., T. L. Madden, A. A. Schaffer, J. Zhang, Z. Zhang, W. Miller, and D. J. Lipman. 1997. Gapped BLAST and PSI-BLAST: A new generation of protein database search programs. Nucleic Acids Res. 25:3389-3402.

APHA. 2004. Standard Methods for the Examination of Dairy Products. 17th ed. American Public Health Association, Washington, DC.

APHA. 2005. Standard Methods for the Examination of Water and Wastewater. 21st ed. American Public Health Association, Washington, DC.

Bej, A. K., S. C. McCarty, and R. M. Atlas. 1991. Detection of coliform bacteria and Escherichia coli by multiplex polymerase chain reaction: Comparison with defined substrate and plating methods for water quality monitoring. Appl. Environ. Microbiol. $57: 2429-2432$.

Bej, A. K., R. J. Steffan, J. DiCesare, L. Haff, and R. M. Atlas. 1990. Detection of coliform bacteria in water by polymerase chain reaction and gene probes. Appl. Environ. Microbiol. 56:307-314.

Bohaychuk, V. M., G. E. Gensler, M. E. McFall, R. K. King, and D. G. Render. 2007. A realtime PCR assay for the detection of Salmonella in a wide variety of food-animal matrices. J. Food Prot. 70:1080-1087.

Bredie, W. L. P., and E. de Boer. 1992. Evaluation of the MPN, Anderson-Baird-Parker, Petrifilm E. coli and Fluorocult ECD method for enumeration of Escherichia coli in foods of animal origin. Food Microbiol. 161:197-208.

Cheng, C.-M., K. T. Van, W. Lin, and R. M. Ruby. 2009. Interlaboratory validation of a real-time PCR 24-hour rapid method for detection of Salmonella in foods. J. Food Prot. 72:945-951.

Chenna, R., H. Sugawara, T. Koike, R. Lopez, T. J. Gibson, D. J. Higgins, and J. D. Thompson. 2003. Multiple sequence alignment 
with the Clustal series of programs. Nucleic Acids Res. 31:34973500 .

Chopin, A., M. C. Chopin, A. Moillo-Batt, and P. Langella. 1984. Two plasmid-determined restriction and modification systems in Streptococcus lactis. Plasmid 11:260-263.

De Buyser, M. L., B. Dufour, M. Maire, and V. Lafarge. 2001. Implication of milk and milk products in food-borne diseases in France and in different industrialized countries. Int. J. Food Microbiol. 67:1-17.

Drancourt, M., C. Bollet, A. Carta, and P. Rousselier. 2001. Phylogenetic analyses of Klebsiella species delineate Klebsiella and Raoultella gen. nov., with description of Raoultella ornithinolytica comb. nov., Raoultella terrigena comb. nov. and Raoultella planticola comb. nov. Int. J. Syst. Evol. Microbiol. 51:925-932.

Elizaquível, P., and R. Aznar. 2008. A multiplex RTi-PCR reaction for simultaneous detection of Escherichia coli O157:H7, Salmonella spp. and Staphylococcus aureus on fresh, minimally processed vegetables. Food Microbiol. 25:705-713.

Feng, P. 1997. Impact of molecular biology on the detection of foodborne pathogens. Mol. Biotechnol. 7:267-278.

Feng, P. C. S., and P. A. Hartman. 1982. Fluorogenic assays for immediate confirmation of Escherichia coli. Appl. Environ. Microbiol. 43:1320-1329.

Foulds, I., R. A. Guy, A. Kapoor, C. Xiao, U. J. Krull, and P. A. Horgen. 2002. Application of quantitative real-time PCR with duallabeled hydrolysis probes to microbial water quality monitoring. J. Biomol. Tech. 13:272-276.

Fukushima, H., Y. Tsunomori, and R. Seki. 2003. Duplex real-time SYBR green PCR assays for detection of 17 species of food- or waterborne pathogens in stools. J. Clin. Microbiol. 41:51345146.

Hein, I., A. Lehner, P. Rieck, K. Klein, E. Brandl, and M. Wagner. 2001. Comparison of different approaches to quantify Staphylococcus aureus cells by real-time quantitative PCR and application of this technique for examination of cheese. Appl. Environ. Microbiol. 67:3122-3126.

Hill, W. E. 1996. The polymerase chain reaction: Applications for the detection of foodborne pathogens. Crit. Rev. Food Sci. Nutr. $36: 123-173$.

Holicka, J., R. A. Guy, A. Kapoor, D. Shepherd, and P. A. Horgen. 2006. A rapid (one day), sensitive real-time polymerase chain reaction assay for detecting Escherichia coli O157:H7 in ground beef. Can. J. Microbiol. 52:992-998.

Ito, H., N. Kido, Y. Arakawa, M. Ohta, T. Sugiyama, and N. Kato. 1991. Possible mechanisms underlying the slow lactose fermentation phenotype in Shigella spp. Appl. Environ. Microbiol. 57:29122917.

Klein, D., P. Janda, R. Steinborn, M. Müller, B. Salmons, and W. H. Günzburg. 1999. Proviral load determination of different feline immunodeficiency virus isolates using real-time polymerase chain reaction: Influence of mismatches on quantification. Electrophoresis 20:291-299.

Leclerc, H., D. A. A. Mossel, S. C. Edberg, and C. B. Struijk. 2001. Advances in the bacteriology of the coliform group: Their suitability as markers of microbial water safety. Annu. Rev. Microbiol. 55:201-234.
Martín, M. C., M. A. González-Hevia, J. A. Alvarez-Riesgo, and M. C. Mendoza. 2001. Salmonella serotype Virchow causing salmonellosis in a Spanish region. Characterization and survey of clones by DNA fingerprinting, phage typing and antimicrobial resistance. Eur. J. Epidemiol. 17:31-40.

Murphy, S. C., and K. J. Boor. 2000. Trouble-shooting sources and causes of high bacteria counts in raw milk. Dairy Food Environ. Sanit. 20:606-611.

Ochman, H., J. G. Lawrence, and E. A. Groisman. 2000. Lateral gene transfer and the nature of bacterial innovation. Nature 405:299 304.

Omiccioli, E., G. Amagliani, G. Brandi, and M. Magnani. 2009. A new platform for real-time detection of Salmonella spp., Listeria monocytogenes and Escherichia coli $\mathrm{O} 157$ in milk. Food Microbiol. $26: 615-622$.

Oravcová, K., T. Kuchta, and E. Kaclíková. 2007. A novel real-time PCR-based method for the detection of Listeria monocytogenes in food. Lett. Appl. Microbiol. 45:568-573.

Powe, B., and R. J. Gross. 1984. Shigella Castellani and Chalmers, 1919, 936. Pages 423-427 in Bergey's Manual of Systematic Bacteriology. Vol. 1. N. R. Krieg and J. G. Holt, ed. Williams \& Wilkins Co., Baltimore, MD.

Tantawiwat, S., U. Tansuphasiri, W. Wongwit, V. Wongchtigul, and D. Kitayaporn. 2005. Development of multiplex PCR for detection of total coliform bacteria for Eschericha coli and Clostridium perfringens in drinking water. Southeast Asian J. Trop. Med. Public Health 36:162-169.

Thompson, J. D., D. G. Higgins, and T. J. Gibson. 1994. CLUSTAL $\mathrm{W}$ : Improving the sensitivity of progressive multiple sequence alignment through sequence weighting, position-specific gap penalties and weight matrix choice. Nucleic Acids Res. 22:46734680.

Usera, M. A., A. Rodriguez, A. Echeita, and R. Cano. 1998. Multiple analysis of a foodborne outbreak caused by infant formula contaminated by an atypical Salmonella virchow strain. Eur. J. Clin. Microbiol. Infect. Dis. 17:551-555.

Wei, J., M. B. Goldberg, V. Burland, M. M. Venkatesan, W. Deng, G. Fournier, G. F. Mayhew, G. I. I. I. Plunkett, D. J. Rose, A. Darling, B. Mau, N. T. Perna, S. M. Payne, L. J. Runyen-Janecky, S. Zhou, D. C. Schwartz, and F. R. Blattner. 2003. Complete genome sequence and comparative genomics of Shigella flexneri serotype 2a strain 2457T. Infect. Immun. 71:2775-2786.

Winfield, M. D., and E. A. Groisman. 2003. Role of nonhost environments in the lifestyles of Salmonella and Escherichia coli. Appl. Environ. Microbiol. 69:3687-3694.

Yang, F., J. Yang, X. Zhang, L. Chen, Y. Jiang, Y. Yan, X. Tang, J. Wang, Z. Xiong, J. Dong, Y. Xue, Y. Zhu, X. Xu, L. Sun, S. Chen, H. Nie, J. Peng, J. Xu, Y. Wang, Z. Yuan, Y. Wen, Z. Yao, Y. Shen, B. Qiang, Y. Hou, J. Yu, and Q. Jin. 2005. Genome dynamics and diversity of Shigella species, the etiologic agents of bacillary dysentery. Nucleic Acids Res. 33:6445-6458.

Zottola, E. A., and L. B. Smith. 1991. Pathogens in cheese. Food Microbiol. 8:171-182. 